\title{
Small-scale lab analysis of the ground freezing effect on the thermal performance of a Flat-Panel ground heat exchanger
}

\author{
Jingyu Cao ${ }^{\mathrm{a}}$, Michele Bottarelli ${ }^{\mathrm{b}, *}$, Marco Bortoloni ${ }^{\mathrm{c}}$, Gang Pei ${ }^{\mathrm{a}}$ \\ a Department of Thermal Science and Energy Engineering, University of Science and Technology of China, Hefei 230027, China \\ ${ }^{\mathrm{b}}$ Department of Architecture, University of Ferrara, Via Quartieri 8, Ferrara 44121, Italy \\ c TekneHub Laboratory, University of Ferrara, Via Saragat 13, Ferrara 44122, Italy
}

\section{A R T I C L E I N F O}

Keywords:

Flat-Panel ground heat exchanger

Water latent heat

Thermal performance

Lab-scale testing

\begin{abstract}
A B S T R A C T
Shallow ground heat exchangers are increasingly studied due to their advantages in cost and long-term energy performance stability when coupled with heat pumps for space heating and cooling. As for borehole heat exchangers, the backfilling material affects significantly the operating efficiency of the whole system, mainly driven by the low thermal diffusivity of the soil. To enhance the heat transfer, the mixing of the backfilling material with phase change materials (PCMs) is a novel strategy still partially investigated, especially with regards of the heat pump on/off cycling. This study presents the results of experimental tests carried out at lab-scale to analyse the performance of a shallow Flat-Panel ground heat exchanger (FGHE) coupled with water-sand mixture. Firstly, the comparison between FGHEs coupled with dry sand and water-sand mixture is performed; then, the impact of latent heat resulting from freezing is further studied in three on/off operating modes. A maximum of $31.6 \%$ increment in heat transfer efficiency is observed in wet conditions and for the highest on/off frequency. Therefore, coupling FGHE with water-sand mixture enhances the heat transfer, especially in icing interval and when combined with a suitable on/off operating frequency.
\end{abstract}

\begin{tabular}{|c|c|}
\hline \multicolumn{2}{|c|}{ Nomenclature } \\
\hline C & Specific heat $\left[\mathrm{kJ} / \mathrm{kg}^{\circ} \mathrm{C}\right]$ \\
\hline$Q^{\cdot}$ & Heat transfer rate $[\mathrm{kW}]$ \\
\hline$T$ & Temperature $\left[{ }^{\circ} \mathrm{C}\right]$ \\
\hline$\dot{V}_{g}$ & Volume flow rate $\left[\mathrm{m}^{3} / \mathrm{s}\right]$ \\
\hline \multicolumn{2}{|c|}{ Greek letters } \\
\hline$\rho$ & Density $\left[\mathrm{kg} / \mathrm{m}^{3}\right]$ \\
\hline \multicolumn{2}{|c|}{ Subscripts } \\
\hline A & Box A \\
\hline$B$ & Box B \\
\hline$g$ & Working fluid \\
\hline $0 \sim 6$ & Temperature probes \\
\hline
\end{tabular}

\footnotetext{
* Corresponding author.

Email address: michele.bottarelli@unife.it (M. Bottarelli)
}

\section{Introduction}

Ground coupled heat pumps (GCHPs) have been widely used as a sustainable energy technology for heating and cooling of buildings due to its high efficiency (Omer, 2008; Zhai et al., 2011; Sarbu and Sebarchievici, 2014). It is particularly useful in cold and humid regions because it can avoid the frosting problem affecting air source heat pumps; therefore, significant energy consumption can be saved (Bayer et al., 2012; Self et al., 2013; Soni et al., 2015). In GCHP systems, the ground heat exchangers (GHEs) works as a key component and could be roughly classified into vertical and horizontal types according to their arrangement (Soni et al., 2015). In the vertical solution, GHEs are installed into boreholes drilled up to hundreds meters deep to exploit the great heat storage capacity of the ground and higher temperatures (Li and Lai, 2015; Rivera et al., 2015; Cao et al., 2017). This type has been widely utilized for high-rise buildings; however, initial costs and install and maintenance difficulties are significant drawbacks of this technology (Soni et al., 2016). On the contrary, the horizontal installation type has remarkable advantages because the heat exchanger is 
placed few meters deep in shallow ground (Gabrielli and Bottarelli, 2016). Unlike the stable geothermal source in borehole systems, the shallow ground source may mainly serve as a temporary solar energy buffer, as a consequence of the close dependence on environmental conditions. Even if the seasonal weather conditions affect the performance of horizontal GHEs, at the same time they can avoid ground thermal drifts after long-term operation, that on the contrary affect the vertical GHEs. Therefore, increasing attention has been devoted to the horizontal GHEs in recent years, particularly in field of compact GCHP systems (Chalhou et al., 2017; Han et al., 2017; Hua et al., 2017).

Anyway, the low thermal diffusivity of the ground impacts heavily on the GHE size, and therefore on the installation costs. Enhancing the thermal properties of the backfilling material has been considered an effective solution, especially with regard of the heat conductivity (Erol and François, 2014; Kim et al., 2017). Besides, taking into account the on/off operating mode of normal heat pump system, the usage of phase change materials (PCMs) in the ground close to the GHEs can improve the on-time heat transfer capability (Farida et al., 2004) by using the off-time as thermal buffer recovery. This strategy has been studied since 1996 and in different conditions (Rabin and Korin, 1996; Lei and Zhu, 2009; Wu, 2011). Closer examination was carried out by Wang et al. by adopting PCMs as grout to improve the heat capacity of soil. The variation of heat transfer characteristic of borehole heat exchanger was evaluated by a 3-dimensional numerical heat transfer simulation. The results show that the land area can be reduced effectively with PCMs as backfilling; however, the heat transfer improvement is needed due to the low conductivity of the selected PCMs (Wang et al., 2014). Li et al. proposed a shape-stabilized phase change backfilling material for U-tube heat exchanger. It referred to a mixture of decanoic acid and lauric acid. The shape-stabilized PCM backfilling could improve the heat exchange capability up to $37 \%$ and showed significant influence on heat pump coefficient (Li et al., 2016). Qi et al. tested the performance of vertical GHE coupled with four backfilling materials, including soil, paraffin RT27, acid and enhanced acid PCM. The efficiency improvement was analysed on the basis of its small thermal effects radius and consistent temperature in the phase change process (Qi et al., 2016).

Though several analyses were done about this topic, they were mainly limited in the field of vertical system, and few literatures were related to horizontal GHEs. Bottarelli et al. studied the effect of PCMs on the performance of a horizontal and shallow Flat-Panel GHE, whose flat shape and its edgeways installation into a narrow trench well adapts to similar applications (Bottarelli et al., 2015a,).

However, the significant cost increment caused by the large amount of PCMs, their low heat conductivity and environmental impact are still unsolved problems for GCHPs. To avoid them, Eslami-nejad and Bernier proposed to utilize latent heat from groundwater freezing. Based on this low-cost PCM, 38\% of the borehole depth can be reduced for the same heat pump system (Eslami-nejad and Bernier, 2012). Yang et al. built a two-dimensional heat transfer model to study the effects of soil freezing on underground temperature variations of soil around GHEs. It further proved that the soil freezing lessened the soil temperature drop, increased the temperature difference and finally helped to shorten the length of GHE (Yang et al., 2015). Particularly, Gan et al. preliminarily simulated the effect of soil freezing on the heat exchanger performance of horizontal GHE. The significant increase in the specific heat extraction resulting from soil freezing was observed and it could be beneficial for continuous operation of a heat pump (Gan, 2013). Recently, a three-dimensional model was used by Zheng et al. to simulate the effect of latent heat from groundwater freezing; results confirm that exploitation of latent heat through groundwater freezing is economically attractive with low electricity price (Zheng et al., 2016).

To further explore this potential benefit for horizontal GHEs, we experimentally analyse in this study the usage of water as PCM backfilling material of the sand filling the trench containing a Flat-Panel ground heat exchanger (FGHE), similar to what was studied by Bottarelli et al. (2015a). The use of water as a phase change material applies to GCHPs operating with water/glycol mixture as the working fluid. The thermal behaviour of it is significantly related to the heat transfer capability of the FGHE. Though numerical analysis on the FGHE coupled with PCMs was carried out (Bottarelli et al., 2015a,b), the experimental approach had still to be investigated, such as the short-term heat transfer behaviour of the FGHE.

\section{Experimental set-up}

An original test rig installed at the TekneHub laboratory of the University di Ferrara (Italy) has been revamped to evaluate the thermal performance of FGHE coupled with shallow water-sand mixture for heat pump systems. As depicted in Fig. 1, the test rig is composed of two insulated boxes A and B, made by $6 \mathrm{~cm}$ thick extruded polystyrene (XPS) with a thermal conductivity of $0.04 \mathrm{~W} / \mathrm{mK}$. The top thermal insulating layer can be removed. A plastic tub is placed inside the insulating box and the interstice between them $(6 \mathrm{~cm})$ is filled with sawdust to furtherly reduce heat loss. As shown in Fig. 2, a FGHE is located in the middle of each box and installed into a trench with aluminium walls. The tub and the trench volume (i.e. the soil volume) are initially filled by dry sand. Three samples were taken in order evaluate the dry sand properties. The density and porosity were experimentally measured to be on average of $1515 \mathrm{~kg} / \mathrm{m}^{3}$ and 0.36 , respectively. The average specific heat capacity equal to $952 \mathrm{~J} / \mathrm{kgK}$ was estimated by means of a differential scanning calorimeter (DSC) at the Istanbul Technical Univer-

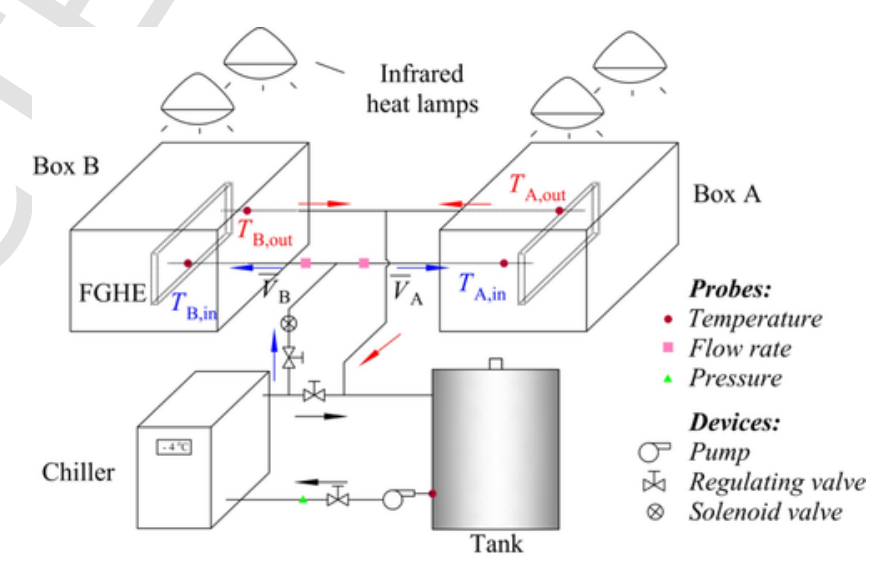

(a) Set up

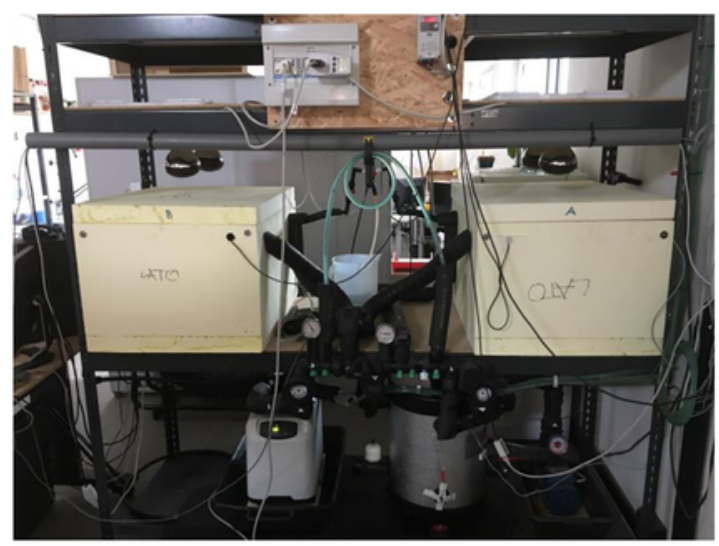

(b) Test rig

Fig. 1. Test rig and probes. 


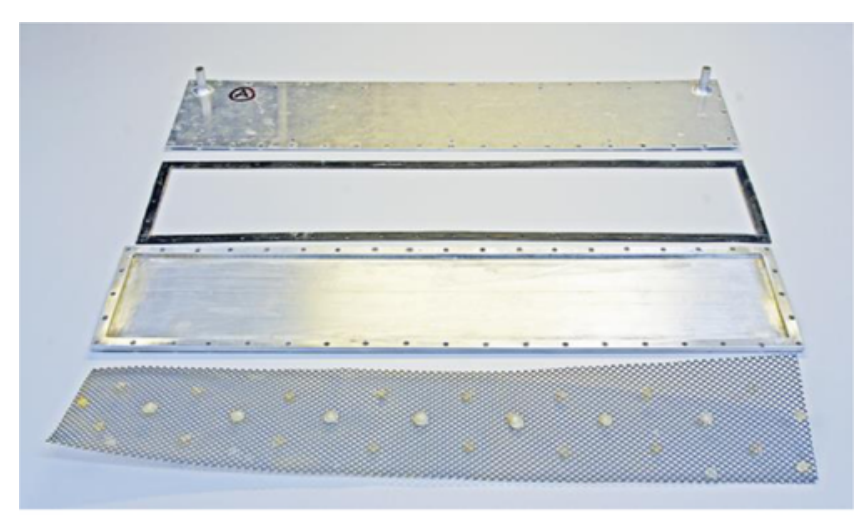

(a) Flat-panel ground heat exchanger

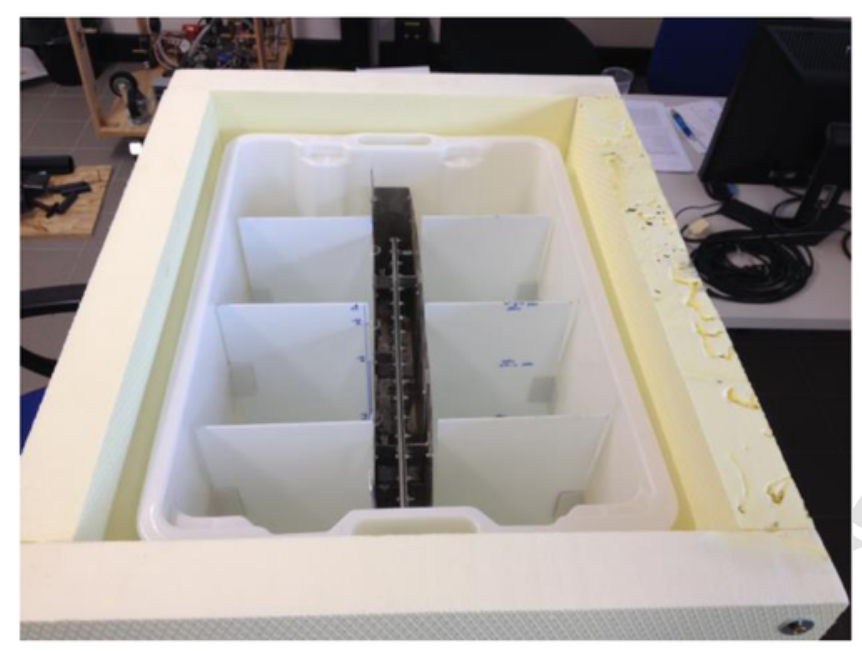

\section{(b) Inner structure of each box}

Fig. 2. Reduced-scale experimental facilities.

sity. Finally, the soil thermal conductivity $(0.35 \mathrm{~W} / \mathrm{mK})$ has been calibrated against experimental data, given the estimated density and specific heat capacity, by applying the analytical solution of the 1D transient heat conduction in a homogeneous semi-infinite solid (Bottarelli, 2013).

The FGHE consists of two fastened machined aluminium plates inside which a plastic net increase the mixing of the working fluid. The two FGHEs and the related soil volume are taken 10 times scaled down from a real case to be analysed at lab-scale, and only the trench of the box A is filled with water, whereas that in box B changes according the test case among dry or salt-water, as later described. The cross-section in Fig. 3 and the detailed dimensions in Table 1 shows the accurate locations of the FGHE and trench. Besides, on the basis of the $1: 10$ space scale, the time scale and heat transfer scale for the operating FGHE could be calculated as approximately 1:3.16 and 1:10, respectively (Coutinho et al., 2016).

The working fluid for the system is water mixed with polypropylene glycol (40\%). A TECO chiller TC20 (540W), a centrifugal pump PK60 and an insulated tank (50L) are connected by HDPE tubes. Based on this primary loop and two regulating valves, the working fluid can be evenly supplied to the two FGHEs located in box A and B with an adjustable flow rate. The temperature of the working fluid in the tank and in the primary loop is maintained between $-4.0^{\circ} \mathrm{C}$ and $-3.5^{\circ} \mathrm{C}$, according to the start/stop of the chiller. The solenoid valve located at

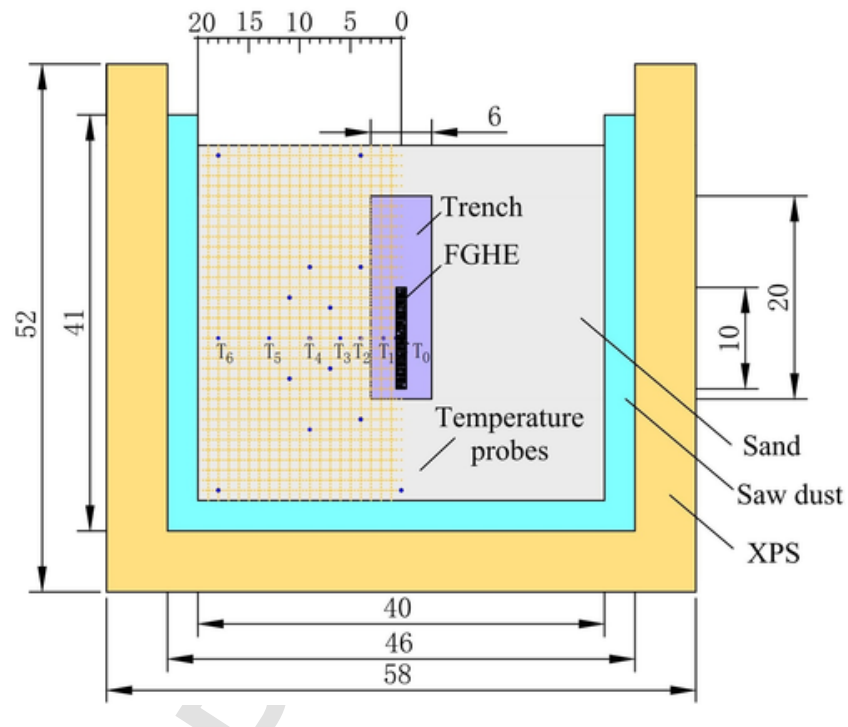

Fig. 3. Cross section and temperature probes.

Table 1

Geometrical parameters.

\begin{tabular}{lllll}
\hline Component & $\begin{array}{l}\text { Length } \\
(\mathrm{cm})\end{array}$ & $\begin{array}{l}\text { Width } \\
(\mathrm{cm})\end{array}$ & $\begin{array}{l}\text { Height } \\
(\mathrm{cm})\end{array}$ & $\begin{array}{l}\text { Volume } \\
(\mathrm{L})\end{array}$ \\
\hline $\begin{array}{l}\text { Flat-Panel heat } \\
\text { exchanger }\end{array}$ & 50 & 1 & 10 & 0.5 \\
$\begin{array}{l}\text { Trench } \\
\begin{array}{l}\text { Sand volume } \\
\text { interior dimension of } \\
\text { box A or B } \\
\text { external dimension of } \\
\text { box A or B }\end{array}\end{array}$ & 55 & 6 & 20 & 6.6 \\
\hline
\end{tabular}

the inlet of the FGHEs is controlled by an on/off timer; thus, the on/ off cycling time of the FGHEs can be set. Two infrared heat lamps are installed above each box at a distance of $20 \mathrm{~cm}$ from the sand surface, to be used as radiant heat source. The lamps are connected to an energy meter and are controlled by a dimmer in order to lower the radiant power output. The flow rate in the primary loop is controlled by the regulating valve and the frequency of the pump PK60, which could provide a maximum $40 \mathrm{~L} / \mathrm{min}$ flow rate with an operating frequency of $50 \mathrm{~Hz}$. The test rig is located in an air-conditioned room where the set-point temperature is $26^{\circ} \mathrm{C}$. All tubes and valves are thermally insulated to maintain the low temperature of the working fluid in the primary loop.

The monitoring system is equipped with several resistance temperature detectors (RTD) produced by SGM LEKTRA which uses a platinum resistor (PTF) as the sensing element. The measurement points in the whole system are shown in Figs. 2 and 3. To evaluate the behaviour of the FGHEs, 4 temperature sensors are installed at their inlets and outlets. The left-hand soil temperature distribution of the central cross-section of the soil field is also monitored by 18 temperature sensors. Particularly, $\mathrm{T}_{1}, \mathrm{~T}_{2}, \mathrm{~T}_{3}, \mathrm{~T}_{4}$ and $\mathrm{T}_{5}$ are located on the perpendicular bisector of the FGHE. Two PBI0212 pulse flow meters are installed at the inlet of each FGHE to measure the flow rate and the signal is recorded every $30 \mathrm{~s}$. An in-house software for data collecting is utilized to record the temperature measurements and the frequency is changed for different test conditions. Moreover, an electronic scale SOEHNLE is used to fill water and $8 \%$ salt solution into the sand inside of the trench of box B. The pressure and flow rate in the primary loop are monitored by pressure sensor EN 836-1 and water flow meter B89, respectively. Detailed 
information on experimental testing and monitoring devices is presented in Table 2.

\section{Experimental methodology}

The comparison tests are performed to study the impact of shallow water-sand mixture on the behaviour of FGHE. For convenience, normal test conditions are adopted unless specific conditions are mentioned: the ambient temperature is controlled at approximately $26^{\circ} \mathrm{C}$. The flow rate of the working fluid in the primary loop is set at $15.4 \mathrm{~L} / \mathrm{min}$, and remains between $-4.0^{\circ} \mathrm{C}$ and $-3.5^{\circ} \mathrm{C}$ according the on/off of the chiller.

Firstly, the trench of box A is filled with $660 \mathrm{~g}$ water, nearly $10 \%$ of the volume of trench, to obtain sand with modest moisture content whereas the sand in the trench of box B is dry. The FGHE in each box is left operating in continuous mode for a long period to reach a thermal steady state of the domain. The effect of the improvement in thermal properties caused by additional water in the trench of box A is observed.

Secondly, the soil in the trench of box B is mixed with $610 \mathrm{~g}$ water and $50 \mathrm{~g}$ salt. The density, thermal conductivity and specific heat of the $8 \%$ salt solution are $1.056 \mathrm{~kg} / \mathrm{m}^{3}, 0.591 \mathrm{~W} / \mathrm{m}^{\circ} \mathrm{C}$ and $3.8 \mathrm{~kJ} / \mathrm{kg}^{\circ} \mathrm{C}$ at $20^{\circ} \mathrm{C}$, which can be considered close enough to pure water, but with a freezing point decreased to $-5^{\circ} \mathrm{C}$, and therefore avoiding the icing in the trench of box B. That was checked in a preliminary test: two test tubes filled with water-sand mixture and salt-water-sand mixture were equipped with RTD temperature sensors and subjected to a temperature decrease in a refrigerator. Results showed that their freezing points are approximately 0.0 and $-5.5^{\circ} \mathrm{C}$, respectively. As a consequence, the thermal properties of soil in both boxes are similar whereas the water-sand mixture in box B cannot freeze even the temperature reaches $-4^{\circ} \mathrm{C}$. Therefore, the effect of phase change of the water-sand mixture is evaluated and directly compared by carrying out three on/off operating modes, corresponding to the real working conditions of ground source heat pump systems. Indeed, the on/off operating mode of the FGHE is considered of great importance for the operating conditions, and is analysed in three test cases as follows:

- Mode 1: the FGHEs in box A and box B work for $3 \mathrm{~h} 10 \mathrm{~min}$ and stop for $4 \mathrm{~h} 25 \mathrm{~min}$. Considering the time scale (1:3.16), it represents a common operating mode of a heat pump system for office building: $10 \mathrm{~h}$ on and $14 \mathrm{~h}$ off in each day. The flow rate in each FGHE is $150 \mathrm{~mL} /$ $\mathrm{min}$. Both of the two boxes are well covered and the radiant heaters are turned off. The temperature data are recorded every $5 \mathrm{~min}$.

- Mode 2: the upper thermal coverings of box A and B are removed and the infrared heat lamps are turned on; $40 \mathrm{~W}$ radiant heat is continuously provided to the upper surface of the sand field in each box, corresponding to about $170 \mathrm{~W} / \mathrm{m}^{2}$. All other conditions remain the same as Mode 1 .

Table 2

Experimental testing and monitoring devices.

\begin{tabular}{|c|c|c|c|}
\hline Device & Specification & Range & Accuracy \\
\hline Pressure sensor & EN 836-1 & 0-1 bar & 0.1 bar \\
\hline $\begin{array}{l}\text { Platinum temperature } \\
\text { sensor }\end{array}$ & RTD & -30 to $125^{\circ} \mathrm{C}$ & $\pm 0.1^{\circ} \mathrm{C}$ \\
\hline Water flow meter & B89 & / & $0.1 \mathrm{~L}$ \\
\hline Pulse flow meter & PBI0212 & $0.01-0.9 \mathrm{~L} / \mathrm{min}$ & $\pm 2 \%$ \\
\hline Electronic scale & SOEHNLE & $0-5000 \mathrm{~g}$ & $1 \mathrm{~g}$ \\
\hline $\begin{array}{l}\text { Pause-work cycle } \\
\text { timer }\end{array}$ & $\mathrm{TC} / 1$ & $0.2 \mathrm{~s}-10 \mathrm{gg}$ & $\pm 0.2 \mathrm{~s}$ \\
\hline
\end{tabular}

- Mode 3: the FGHEs in box A and box B run in a quick on/off mode and the working fluid flows for $5 \mathrm{~min}$ and stops in next $10 \mathrm{~min}$. The heaters are all turned off and the two boxes are well covered. The flow rate in each FGHE is increased to $250 \mathrm{~mL} / \mathrm{min}$; thus, the temperature in each trench can reach $0^{\circ} \mathrm{C}$ even with a low operation ratio. Since the on/off cycle is much shorter than the previous modes, the interval of temperature data acquisition is decreased to $30 \mathrm{~s}$.

The heat transfer rate of each FGHE is calculated as follow:

$\dot{Q}=\rho_{g} \dot{V}_{g} C_{g}\left(T_{g, \text { out }}-T_{g, \text { in }}\right)$

where $\rho_{g}$ is the density $\left(1.1 \mathrm{~kg} / \mathrm{m}^{3}\right)$ and $C_{g}$ is the specific heat $(3.4 \mathrm{~kJ} /$ $\mathrm{kgK}$ ) of the working fluid, $V_{g}$ is its volume flow rate, $T_{g, \text { in }}$ and $T_{g, \text { out }}$ are its measured inlet and outlet temperatures, respectively.

\section{Results and discussion}

\subsection{Comparison test between dry and wet conditions}

To preliminarily analyse the effect of wet against dry conditions (box $\mathrm{A}$ and $\mathrm{B}$, respectively) in the trench on the heat transfer performance, the system was left operate for long time in continuous mode. The temperature variations of feature points and the thermal energy extracted from the FGHEs are shown in Fig. 4. From $0 \mathrm{~h}$ to $7 \mathrm{~h} 35 \mathrm{~min}$, the heat transfer rate in box A decreases from $143.4 \mathrm{~W}$ to $27.4 \mathrm{~W}$ while the heat transfer rate in box B from $63.2 \mathrm{~W}$ to $17.0 \mathrm{~W} ; 1675 \mathrm{~kJ}$ and $875 \mathrm{~kJ}$ heat is extracted from box A and box B, respectively. The phenomenon is mainly caused by the higher thermal conductivity and specific heat of the water-sand mixture in comparison with the dry sand, as the filling of the porous media by water. Based on the higher heat transfer amount, the overall temperature in box A becomes lower than that of box B. Probes 1, 4 and 6 are selected to depict this temperature difference between the two boxes. The temperature differences at probes 4 and 6 stably increase with time whereas that of probe 1 rises in the first $2 \mathrm{~h}$ and then reaches a relative stable period.

After working for $50 \mathrm{~h}$, both box A and B reach steady state conditions, as a consequence of the energy balance according to the surrounding environment. The stabilized heat transfer rates in box A and $\mathrm{B}$ are $15.6 \mathrm{~W}$ and $10.6 \mathrm{~W}$, respectively; on this basis, a significant overall temperature difference between the two boxes appears. The temperatures versus horizontal distance from the centre of the FGHEs after $50 \mathrm{~h}$ of operation are shown in Fig. 5; the measured temperatures are for those points at the same depth from the middle of the FGHE, with the distance of $5,17.5,40,60,90,130$ and $180 \mathrm{~mm}$ away from the

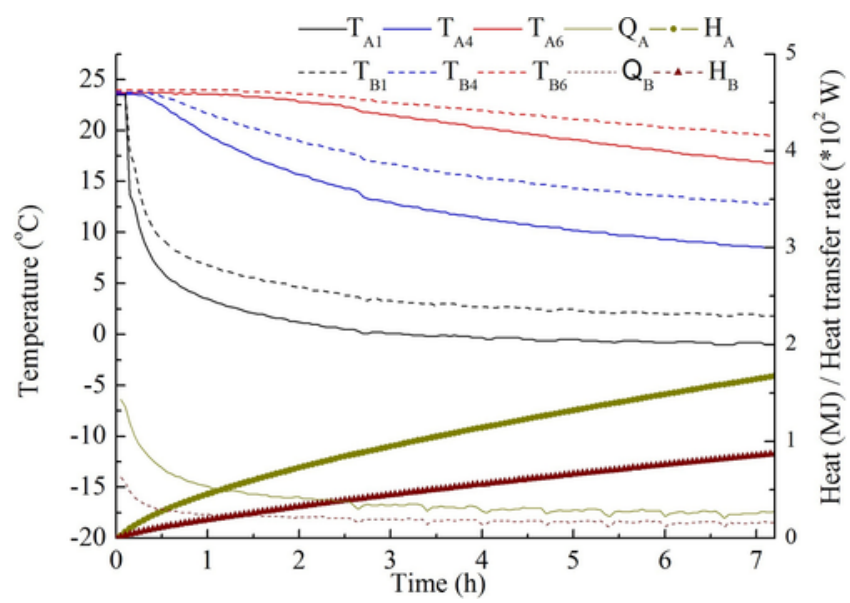

Fig. 4. Heat transfer rate at the heat exchangers coupled with and without of water. 


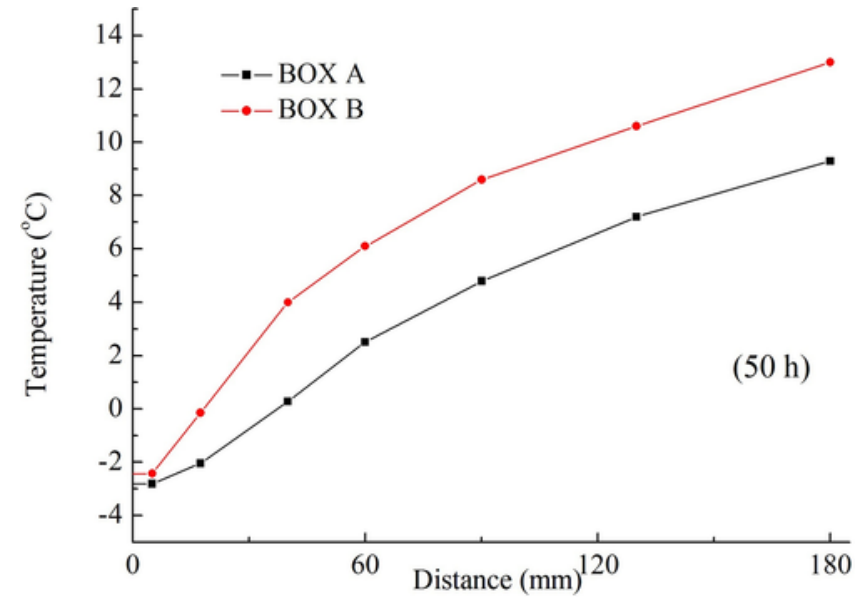

Fig. 5. Temperature versus distance from the centre of the FGHE.

middle axis, respectively. The labels of these probes, in order, are $\mathrm{T}_{0}, \mathrm{~T}_{1}$, $\mathrm{T}_{2}, \mathrm{~T}_{3}, \mathrm{~T}_{4}, \mathrm{~T}_{5}$ and $\mathrm{T}_{6}$. Only $\mathrm{T}_{0}$ and $\mathrm{T}_{1}$ are inside of the trench. As depicted in Fig. 5 , the temperature gradients both decreases with distance, but in the trench of box A, the temperature gradients is much lower than in box B. At each probe outside of the trench, the temperature of box $\mathrm{B}$ is higher than that of box A and the difference remains at approximate $3.6^{\circ} \mathrm{C}$. Around the freezing point, the temperature difference between FGHE and ice-sand mixture is low and the heat transfer capability of FGHE still increases, due to the higher thermal conductivity of the ice-sand mixture.

The aforementioned test preliminarily highlights that the usage of water-sand mixture as backfilling material can improve the thermal properties of the sand within the trench field and significantly increase the heat transfer capability of FGHE.

However, these benefits are mainly caused by the sensible heat transfer, and the impacts of the water latent heat of freezing on the behaviour of FGHE and ground temperature field have yet to be highlighted. Because of the on/off cycling of a GCHP; the effect of the phase change repeating is worthy studying (Bottarelli et al., 2015b). Therefore, the following tests emphasize the comparison between behaviour of FGHEs with and without phase change phenomenon.

\subsection{Mode 1}

To simulate a diurnal on/off working condition, the operating time of the FGHEs was set as $3 \mathrm{~h} 10 \mathrm{~min}$ on and $4 \mathrm{~h} 25 \mathrm{~min}$ off. The FGHE heat transfer performance and the temperature distribution in the two boxes were tested for more than $70 \mathrm{~h}$, to reach steady state conditions. The water freezing was confirmed by excavating the trench of box A at the end of an off-period. As shown in Figs. 6 and 7, five on/off cycles depict the steady fluctuation of the temperature distributions in both boxes, together with the heat transfer rate at the FGHEs. It can be observed that the temperatures of selected probes in box A are always lower than those in box B at any given moment. Inside the trench, for example, $\mathrm{T}_{\mathrm{A} 1}$ increases from $-1.3^{\circ} \mathrm{C}$ to $8.7^{\circ} \mathrm{C}$, while $\mathrm{T}_{\mathrm{B} 1}$ varies from $-1.1^{\circ} \mathrm{C}$ to $9.1^{\circ} \mathrm{C}$ within a fluctuation cycle. Besides, in the area away from the trench, the average temperature of $\mathrm{T}_{\mathrm{A} 5}$ is $10.8^{\circ} \mathrm{C}, 0.5^{\circ} \mathrm{C}$ lower than that of $\mathrm{T}_{\mathrm{B} 5}$, but their fluctuation ranges are both $0.9^{\circ} \mathrm{C}$. Corresponding to the difference between the ground thermal fields in box A and B, clear gap appears in heat balance: the overall energy extracted from box $\mathrm{A}$ is higher than that in box $\mathrm{B}$. The heat transfer rate in box A decrease to $20.7 \mathrm{~W}$ while that in box $B$ is $17.9 \mathrm{~W}$ at the end of each $3.16 \mathrm{~h}$ working period. It is necessary to highlight that the maximum heat transfer rate of each FGHE is not able to be measured accurately because the data acquisition was set as $5 \mathrm{~min}$. Anyway, the average

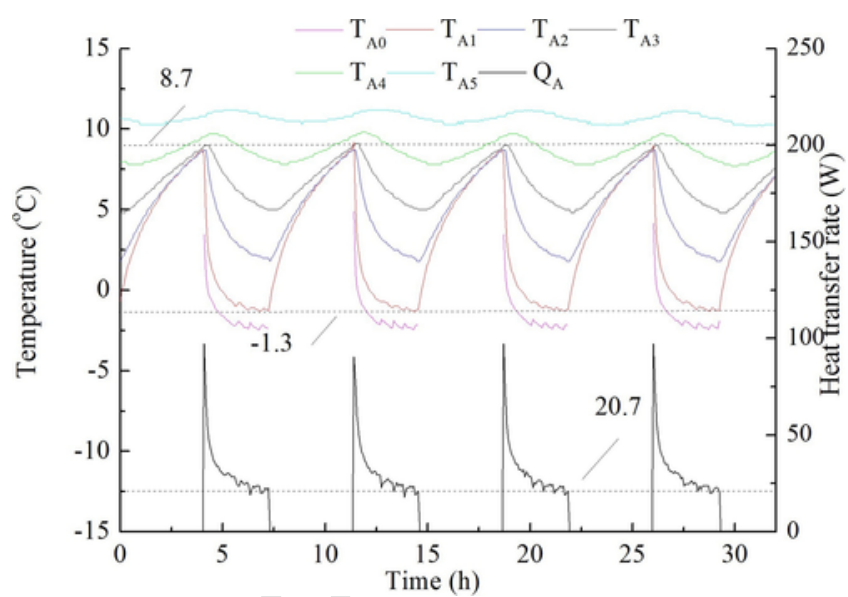

Fig. 6. Behaviour of box A in Mode 1.

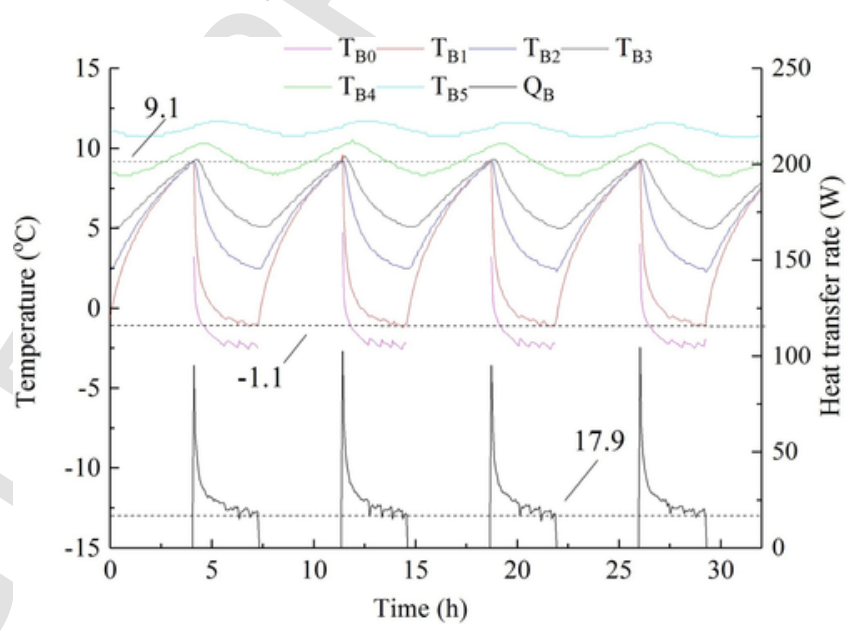

Fig. 7. Behaviour of box B in Mode 1.

heat transfer rates in box A and B during the operating period are $30.9 \mathrm{~W}$ and $26.3 \mathrm{~W}$, equivalent to an average heat flux of $309 \mathrm{~W} / \mathrm{m}^{2}$ and $263 \mathrm{~W} / \mathrm{m}^{2}$, respectively. The total heat transferred from the FGHEs in each operating period can be calculated as $352.1 \mathrm{~kJ}$ and $299.4 \mathrm{~kJ}$, respectively from box A and B. An increment of $17.5 \%$ in heat transfer rate of the FGHE is achieved under the impact of water freezing.

Besides, the thermal fileds in the two boxes are also shown in Figs. 6 and 7. Defining the heat transfer delay as the time for a specified probe spends to reach the maximum or minimum temperature after FGHE operating start or stop, from the start-up moment of FGHE, the time $\mathrm{T}_{\mathrm{A} 5}$ used to reach the maximum temperature is $60 \mathrm{~min}, 10 \mathrm{~min}$ less than that of $\mathrm{T}_{\mathrm{B} 5}$. A temperature drop occurring with a delay of $120 \mathrm{~min}$ at $\mathrm{T}_{\mathrm{A} 5}$ and 165 min at $T_{B 5}$ is observed after the FGHEs stop the cooling of box A and box $\mathrm{B}$ respectively.

To further depict the temperature variation in the sand volume, the isothermal map of the middle section of each box is created on the basis of the software Origin Pro 8. On the basis of layer boundary, the increasing points and the smoothing parameter are set as 500 and 0.001 , respectively. As shown in Figs. 8 and 9, the temperature distributions of box A and B are provided every $1 \mathrm{~h} 35 \mathrm{~min}$ within an on/off cycle. Particularly, the first and third ones are at the starting and stopping moment of FGHEs. Following phenomena can be observed: the overall temperature at the bottom area is higher than the topside of the trench in each box, due to the higher thermal conductivity of the sand-water mixture in the trench in comparison to the dry sand, that lies below the FGHE and the trench. At any moment, the overall temperature in box A 

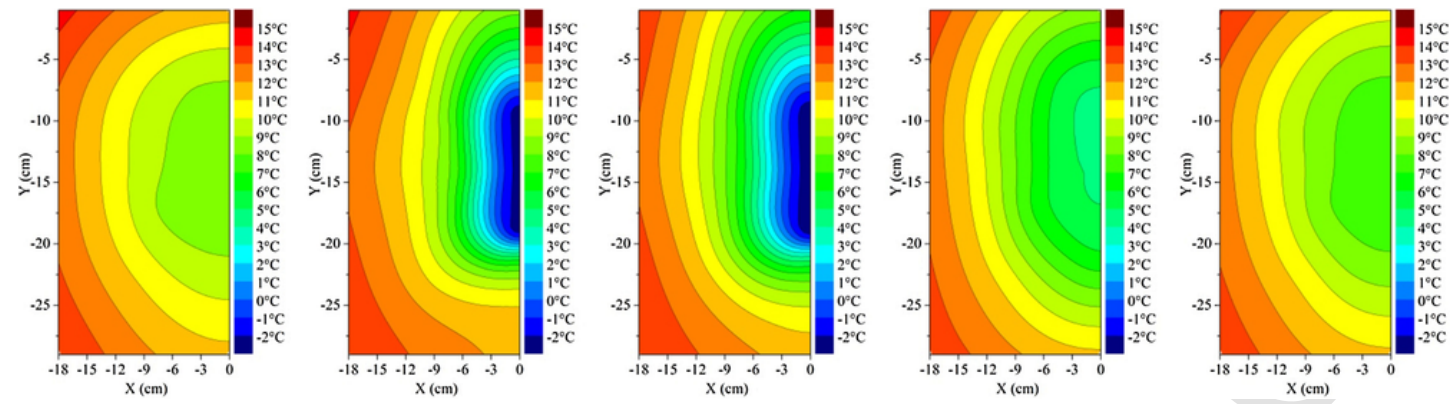

Fig. 8. Temperature distribution of box A versus time in Mode 1.
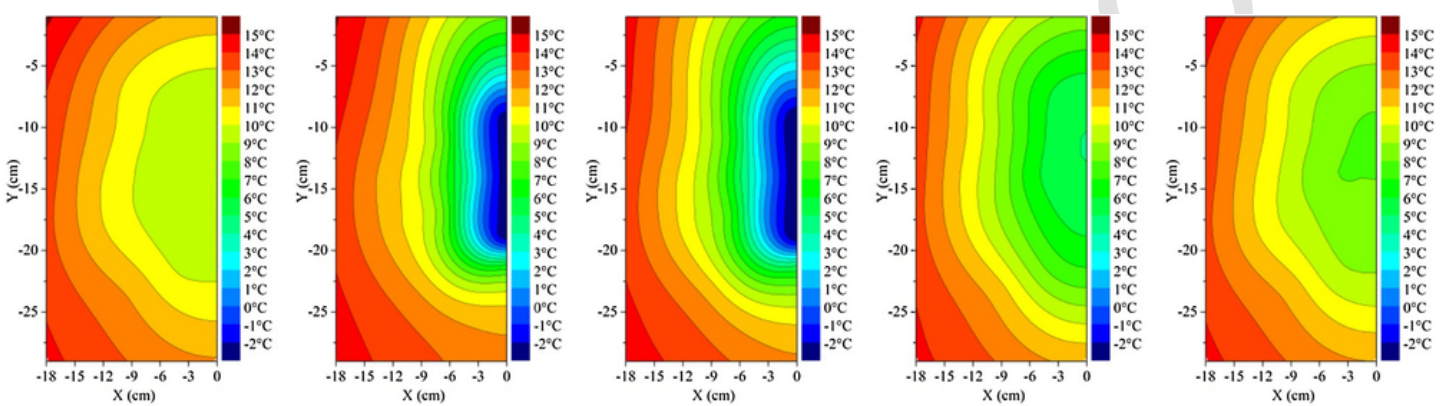

Fig. 9. Temperature distribution of box B versus time in Mode 1.

is lower than box B. Particularly, the sand volume whose temperature is higher than $12^{\circ} \mathrm{C}$ in box B is larger than that in box A at $3 \mathrm{~h} 10 \mathrm{~min}$.

As a consequence, the FGHE coupled with water-sand mixture provides better heat transfer capability. All of the aforementioned results demonstrate that the phase change procedure is advantageous for the heat transfer efficiency of FGHE in an on/off operating mode.

\subsection{Mode 2}

To simulate the case with an external energy supplying, the topside cover of each box was removed and the heaters were turned on. After more than $70 \mathrm{~h}$ of on/off working in Mode 2, the heat and temperature fluctuation were completely stable, similarly to the test in Mode 1 . To compare the ground temperature variations between the two boxes, an on/off cycle is selected and the temperatures of $T_{0}, T_{1}, T_{3}$ and $T_{5}$ versus time are shown in Fig. 10. The temperature fluctuation amplitude of those probes in the two boxes increases due to the infrared heaters: the gap between the maximum and minimum temperature at probe $T_{1}$ in Mode 2 is approximate $16^{\circ} \mathrm{C}, 6^{\circ} \mathrm{C}$ larger than that in Mode 1 . Even this

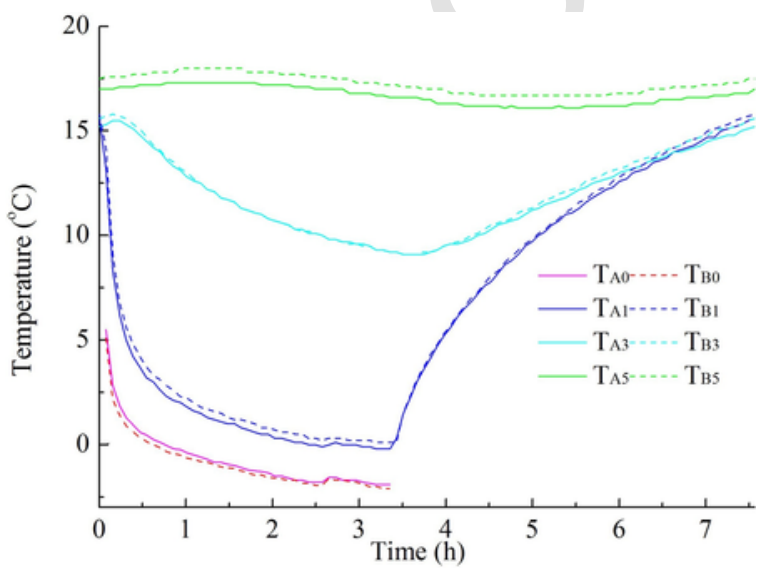

Fig. 10. Temperature variation of observation points in Mode 2. difference gradually decreases with the distance from the FGHE, at probe $\mathrm{T}_{5}$ in Mode 2 is still $1.3^{\circ} \mathrm{C}$ higher than that in Mode 1 . In Mode 2, the different energy extraction by the FGHEs is balanced by the infrared heaters, therefore the temperature difference between the box A and $\mathrm{B}$ is minimum at all the measuring points.

The heat transfer behaviour of FGHEs in box A and B are compared in Fig. 11. At the start-up, the highest heat transfer rates of the FGHEs in box A and B are calculated as $118.9 \mathrm{~W}$ and $103.7 \mathrm{~W}$. As the ground temperature decreases, the heat transfer rates both reduce and reach relative steady status after $3 \mathrm{~h}$; the heat transfer rate of FGHE in box A remains at $33 \mathrm{~W}, 4.6 \mathrm{~W}$ higher than that in box B. During this working period, box A and B are both supplied with a flow rate of $150 \mathrm{~mL} /$ min and the working fluid at $-4^{\circ} \mathrm{C}$. On average, the outlet temperature was $0.7^{\circ} \mathrm{C}$ higher in the box $\mathrm{A}$. The average heat transfer rates in box $\mathrm{A}$ and $\mathrm{B}$ are $44.5 \mathrm{~W}$ and $36.7 \mathrm{~W}$, equivalent to an average heat flux of $445 \mathrm{~W} / \mathrm{m}^{2}$ and $367 \mathrm{~W} / \mathrm{m}^{2}$, respectively. About $570.3 \mathrm{~kJ}$ heat are transferred from the FGHE coupled with water-sand mixture in box A, while that in box B only $474.3 \mathrm{~kJ}$. Under the effect of heat flux flowed from the heaters and the $26^{\circ} \mathrm{C}$ ambient air, the heat supply capability of the

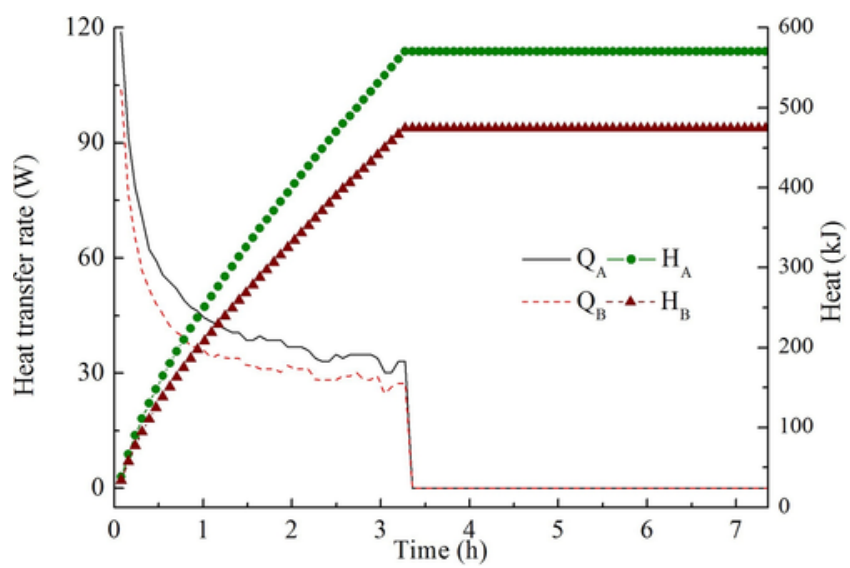

Fig. 11. Heat transferred at the two boxes in Mode 2. 
FGHEs in Mode 2 is much higher than those in Mode 1, particularly, $21.3 \%$ of the heat transfer rate increment is achieved this time.

The isothermal maps are also used to depict the temperature variation of the ground thermal field in Mode 2. Similar to Mode 1, five time steps are selected, and the temperature distributions of the two boxes are shown in Figs. 12 and 13. The high external heat flux causes significant impacts: the temperature of the topside surface of the sand remains relatively high value during all the period. During the stopping time, the lowest temperature field gradually moves to the bottom middle area. In the temperature decrease procedure, the low temperature sand volumes in Mode 2 is much smaller than that in Mode 1. Besides, the sand volume whose temperature is higher than $17^{\circ} \mathrm{C}$ in box $\mathrm{B}$ remains larger than that in box A and this gap is more pronounced compares to Mode 1.

The behaviour of the FGHEs in Mode 2 confirms the aforementioned analysis for Mode 1 . The experiment results further demonstrate that the performance improvement caused by the latent heat of the backfilling material and the improved thermal properties owing to the icing can be enhanced by the ground source.

\subsection{Mode 3}

The previous test was aimed to evaluate the impact of latent heat of water-sand mixture on performance of FGHE and ground thermal field for a low frequency in on/off operating mode. However, small GCHP systems are often used for single-family house and this type sometimes needs to start and stop under high frequency to maintain a stable indoor temperature. On this basis, the working and stopping time of FGHEs in box A and B was reduced to $5 \mathrm{~min}$ and $10 \mathrm{~min}$, respectively, equivalent to 16 and $32 \mathrm{~min}$ at real scale. The temperature distribution in box A reaches a very stable state after $30 \mathrm{~h}$ of on/off test, and so does box B. Similar to the previous modes, freezing area was discovered close to FGHE in box A. The ground temperatures outside of the trench in each box remains relatively stable within a range of $0.1^{\circ} \mathrm{C}$, which cannot be measured by the monitoring system. Only the temperature variation inside of each trench, represented by the probe $T_{1}$, can be observed. The variation of the temperature of backfilling material in box A is $1.3^{\circ} \mathrm{C}, 0.2^{\circ} \mathrm{C}$ higher than that of box B. Results indicate that the impact of the start-stop operation is dampened by the backfilling material. The temperatures of several representative probes in the two boxes are showed in Table 3. At the same position, the temperature difference between the two boxes are within $0.5^{\circ} \mathrm{C}$. The temperature within the trench drops to $-0.7^{\circ} \mathrm{C}$ and $-0.5^{\circ} \mathrm{C}$, in box A and $\mathrm{B}$ respectively. Consequently the water contained in box A is subject to icing, according to the freezing points $\left(0.0^{\circ} \mathrm{C}\right.$ for the water-sand mixture in box $\mathrm{A},-5.5^{\circ} \mathrm{C}$ for the salt-water-sand mixture in box B).

Besides, the average heat transfer efficiency of each FGHE is defined as the average heat transfer rate per unit area, results of Mode 3 are compared with the other two operating modes, as shown in Fig. 14. The average heat transfer rates in box A and B are $48.1 \mathrm{~W}$ and $36.5 \mathrm{~W}$, equivalent to an average heat flux of $481 \mathrm{~W} / \mathrm{m}^{2}$ and $365 \mathrm{~W} / \mathrm{m}^{2}$, respectively. Result shows that a $31.8 \%$ increment in heat transfer rate is generated on the basis of the repeating phase change procedure, which is higher than that in operating Modes 1 and 2. The phenomenon can be analysed on the basis of the comparison between operating Modes 1 and 3: even the external conditions of Mode 1 and 3 are similar, the flow rate of working fluid in Mode 3 is increased, the operating ratio of Mode 3 is smaller and impact of the repeating phase change procedure is enlarged because the start-stop heat transfer oscillation is limited in the trench.

Definitely, the FGHE coupled with water-sand mixture can obtain a relatively better behaviour in Mode 3, compares to the other two operating modes. Therefore, increasing the frequency of start-stop FGHE operating is beneficial for further enhancing the heat transfer efficiency improvement caused by the water freezing.

\section{Conclusions}

In this study, a test rig is set up to study a Flat-Panel ground heat exchanger (FGHE) coupled with shallow water-sand mixture. To evaluate the performance improvement in long-term energy supply, comparison tests are conducted firstly between FGHEs coupled with dry sand and water-sand mixture and then between FGHEs coupled with water-sand mixture and salt-water-sand mixture, where the salt has been used
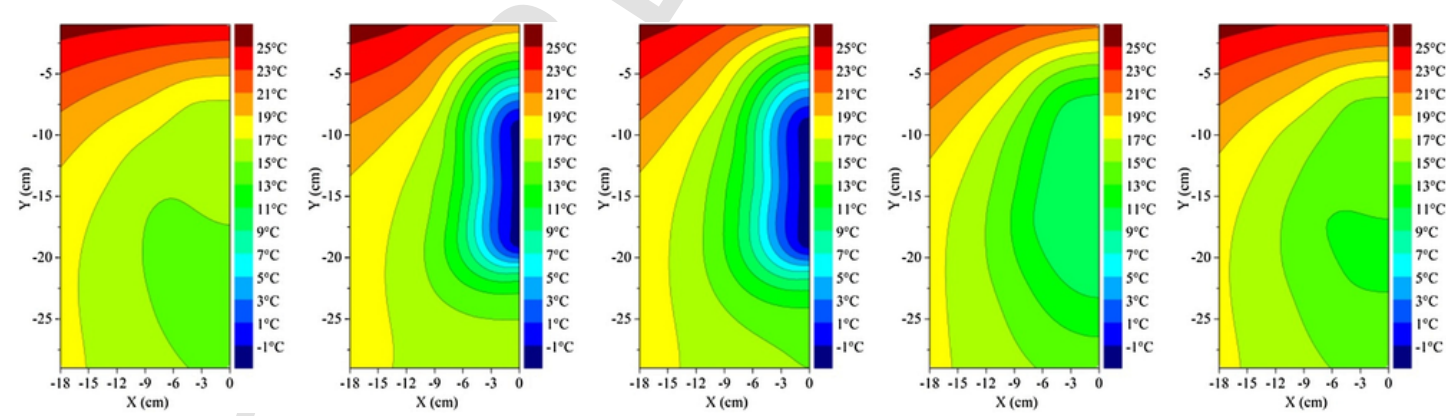

Fig. 12. Temperature distribution of box A versus time in Mode 2 .
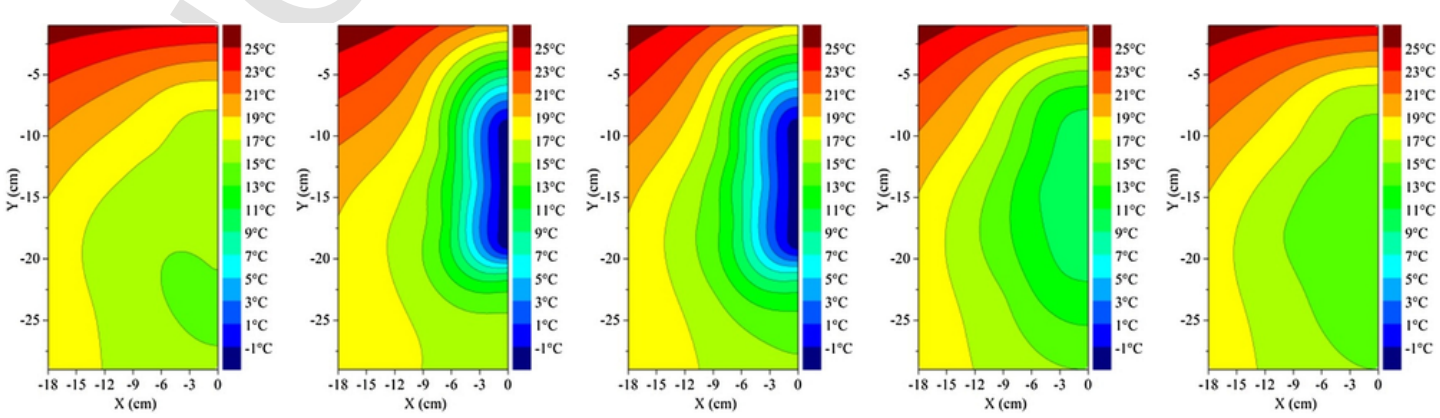

Fig. 13. Temperature distribution of box B versus time in Mode 2 . 
Table 3

Temperature distribution comparison in Mode 3

\begin{tabular}{lll}
\hline Measurement point & Box A & Box B \\
\hline $\mathrm{T}_{1}$ & -0.7 to $0.6^{\circ} \mathrm{C}$ & -0.5 to $0.6^{\circ} \mathrm{C}$ \\
$\mathrm{T}_{2}$ & $1.7^{\circ} \mathrm{C}$ & $2.2^{\circ} \mathrm{C}$ \\
$\mathrm{T}_{3}$ & $3.8^{\circ} \mathrm{C}$ & $4{ }^{\circ} \mathrm{C}$ \\
$\mathrm{T}_{4}$ & $6.1^{\circ} \mathrm{C}$ & $6.6^{\circ} \mathrm{C}$ \\
$\mathrm{T}_{5}$ & $8.3^{\circ} \mathrm{C}$ & $8.8^{\circ} \mathrm{C}$ \\
\hline
\end{tabular}

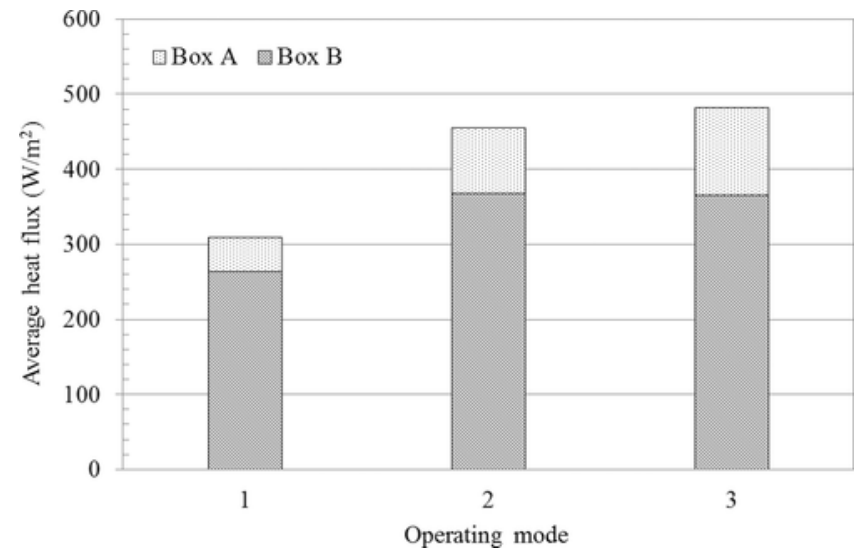

Fig. 14. Average heat transfer of FGHEs in three operating modes.

to avoid the icing of the backfilling mixture. The impact of latent heat is then studied in three on/off FGHE operating modes and with or without infrared heat lamps over the sand surface.

The experimental results allow to remark the following conclusions. The heat transfer rate of FGHE coupled with water-sand mixture is at least $47 \%$ higher than that coupled with dry sand. The better thermal properties of water-sand mixture as backfilling material significantly increase the heat transfer capability of FGHE.

In Mode 1, under the same on/off FGHE operating mode, the average heat transfer rate of the FGHE backfilled with water-sand mixture (box A) is $17.5 \%$ higher than that of salt-water-sand case, owing to the latent heat made available by the freezing/melting. In Mode 2, the average heat transfer rate furtherly increments up to $21.3 \%$ due to the radiant energy supplied by the infrared heat lamps operating over the surface of the sand, because of the only difference with the Mode 1. Finally, in Mode 3, different from Mode 1 for an higher frequency in on/ off FGHE operating mode and higher mass flow rate, furtherly increase the average heat transfer rate up to $31.6 \%$.

Therefore, the latent heat available by the icing of the water filling a porous media can significantly enhance the heat transfer of a FGHE, according its on/off operating mode that affects the melting and thus the heat latent recharge.

\section{Acknowledgements}

The research was funded by the University of Ferrara (Italy) on the basis of the European Regional Development Fund POR-FESR 2014-2020 (HEGOS project, D92I16000050009), the National Science Foundation of China (NSFC 51476159), the National Science and Technology Support Program(2015BAD19B02), the Fundamental Research Funds for the Central Universities and the University of Science and Technology of China, China, for funding the workgroup by means of 2016 Student Exchange Program.

\section{References}

Bayer, P., Saner, D., Bolay, S., Rybach, L., Blum, P., 2012. Greenhouse gas emission savings of ground source heat pump systems in Europe: a review. Renew. Sustain. Energy Rev. 16, 1256-1267.

Bottarelli, M., Bortoloni, M., Su, Y., 2015. Heat transfer analysis of underground thermal energy storage in shallow trenches filled with encapsulated phase change materials. Appl. Therm. Eng. 90, 1044-1051.

Bottarelli, M., Bortoloni, M., Georgiev, A., Aydin, A.A., Su, Y., Yousif, C., 2015. Numerica analysis of a novel ground heat exchanger coupled with phase change materials. Appl. Therm. Eng. 88, 369-375.

Bottarelli, M., 2013. A preliminary testing of a flat panel ground heat exchanger. Int. J. Low-Carbon Technol. 8, 80-87.

Cao, S., Kong, X., Deng, Y., Zhang, W., Yang, L., Ye, Z., 2017. Investigation on thermal performance of steel heat exchanger for ground source heat pump systems using full-scale experiments and numerical simulations. Appl. Therm. Eng. 115, 91-98.

Chalhou, M., Bernier, M., Coquet, Y., Philippe, M., 2017. A simple heat and moisture transfer model to predict ground temperature for shallow ground heat exchangers. Renew. Energy 103, 295-307.

Coutinho, C.P., Baptista, A.J., Rodrigues, J.D., 2016. Reduced scale models based on similitude theory: a review up to 2015. Eng. Struct. 119, 81-94.

Erol, S., François, B., 2014. Efficiency of various grouting materials for borehole heat exchangers. Appl. Therm. Eng. 70, 788-799.

Eslami-nejad, P., Bernier, M., 2012. Freezing of geothermal borehole surroundings: a numerical and experimental assessment with applications. Appl. Energy 98, 333-345.

Farida, M.M., Khudhaira, A.M., Razackb, S.A.K., Al-Hallajb, S., 2004. A review on phase change energy storage: materials and applications. Energy Convers. Manage. 45, $1597-1615$.

Gabrielli, L., Bottarelli, M., 2016. Financial and economic analysis for ground-coupled heat pumps using shallow ground heat exchangers. Sustain. Cities Soc. 20, 71-80.

Gan, G., 2013. Dynamic thermal modelling of horizontal ground-source heat pumps. Int. J. Low-Carbon Technol. 8, 95-105.

Han

et al.,

2017. C. Han, K.M. Ellett, S. Naylor, X. Yu, Influence of local geological data on the performance of horizontal ground-coupled heat pump system integrated with building thermal loads, Renew. Energy 113 (2017) 1046-1055.

Hua, J., Li, G., Zhao, X., Wu, W., Li, D., Li, Q., 2017. The hot stack performance of the shallow geothermal heat pump system with/without intensification state of groundwater seepage in Nanjing (China). Energy Build. 150, 558-566.

Kim, D., Kim, G., Kim, D., Baek, H., 2017. Experimental and numerical investigation of thermal properties of cement-based grouts used for vertical ground heat exchanger. Renew. Energy 112, 260-267. Lei

and

Zhu,

2009. H. Lei, N. Zhu, Analysis of phase change materials (PCMs) used for borehole fill materials, GRC Trans. 33 (2009) 93-98.

Li, M., Lai, A.C.K., 2015. Review of analytical models for heat transfer by vertical ground heat exchangers (GHEs): a perspective of time and space scales. Appl. Energy 151, $178-191$.

Li, X., Tong, C., Duanmu, L., Liu, L., 2016. Research on U-tube heat exchanger with shape-stabilized phase change backfill material. Procedia Eng. 146, 640-647.

Omer, A.M., 2008. Ground-source heat pumps systems and applications. Renew. Sustain. Energy Rev. 12, 344-371.

Qi, D., Pu, L., Sun, F., Li, Y., 2016. Numerical investigation on thermal performance of ground heat exchangers using phase change materials as grout for ground source heat pump system. Appl. Therm. Eng. 106, 1023-1032.

Rabin, Y., Korin, E., 1996. Incorporation of phase-change materials into a ground thermal energy storage system: theoretical study. J. Energy Res. Technol. 118, 237-241.

Rivera, J.A., Blum, P., Bayer, P., 2015. Ground energy balance for borehole heat exchangers: vertical fluxes, ground water and storage. Renew. Energy 83, 1341-1351.

Sarbu, I., Sebarchievici, C., 2014. General review of ground-source heat pump systems for heating and cooling of buildings. Energy Build. 70, 441-454.

Self, Stuart J., Reddy, Bale V., Rosen, Marc A., 2013. Geothermal heat pump systems: status review and comparison with other heating options. Appl. Energy 101, 341-348.

Soni, S.K., Pandey, M., Bartaria, V.N., 2015. Ground coupled heat exchangers: a review and applications. Renew. Sustain. Energy Rev. 47, 83-92.

Soni, S.K., Pandey, M., Bartaria, V.N., 2016. Hybrid ground coupled heat exchanger systems for space heating/cooling applications: a review. Renew. Sustain. Energy Rev. 60, 724-738.

Wang, J.L., De Zhao, J., Liu, N., 2014. Numerical simulation of borehole heat transfer with phase change material as grout. Appl. Mech. Mater. 577, 44-47.

Wu, Y., 2011. Analytical and Experimental Study of Phase Change Materials Used as Backfill Material for Borehole Heat Exchangers. Tianjin University.

Yang, W., Kong, L., Chen, Y., 2015. Numerical evaluation on the effects of soil freezing on underground temperature variations of soil around ground heat exchangers. Appl. Therm. Eng. 75, 259-269.

Zhai, X.Q., Qu, M., Yu, X., Yang, Y., Wang, R.Z., 2011. A review for the applications and integrated approaches of ground-coupled heat pump systems. Renew. Sustain. Energy Rev. 15, 3133-3140.

Zheng, T., Shao, H., Schelenz, S., Hein, P., Vienken, T., Pang, Z., Kolditz, O., Nagel, Thomas, 2016. Efficiency and economic analysis of utilizing latent heat from groundwater freezing in the context of borehole heat exchanger coupled ground source heat pump systems. Appl. Therm. Eng. 105, 314-326. 